\title{
EFECTOS DE EXTRACTOS ACUOSOS DEL FOLLAJE DEL COROCILLO (CYPERUS ROTUNDUS L.) SOBRE LA GERMINACIÓN DE SEMILLAS Y EL CRECIMIENTO DE PLÁNTULAS DE AJONJOLÍ (SESAMUM INDICUM L.) CV. ARAPATOL S-15
}

\author{
EFFECTS OF FOLIAGE WATER EXTRACTS OF PURPLE NUTSEDGE \\ (CYPERUS ROTUNDUS L.) ON SEED GERMINATION AND SEEDLING \\ GROWTH OF SESAME (SESAMUM INDICUM L.) CV. ARAPATOL S-15
}

\author{
José A. Laynez-Garsaball ${ }^{1}$; Jesús Rafael Méndez-Natera ${ }^{1}$
}

\section{RESUMEN}

\begin{abstract}
Este estudio se realizó con objeto de determinar los efectos de extractos acuosos del follaje del corocillo (Cyperus rotundus L.) sobre germinación de semillas y crecimiento de plántulas de ajonjolí (Sesamum indicum L.) variedad Arapatol S-15. Follaje de plantas de corocillo de 15 días fue empleado para preparar un extracto $15 \%$ p/v, y por dilución extractos al 0;0,5;1,0;1,5 y 2,0\%

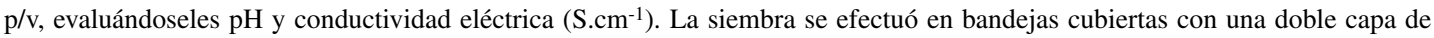
papel absorbente sobre la que se colocaron 25 semillas/bandeja, dejadas al descubierto y regadas tres veces al día con los extractos, el control se regó con agua corriente. El diseño estadístico fue de bloques al azar con cinco concentraciones de extracto y 4 repeticiones. A los 12 días después de la siembra se determinaron los diferentes parámetros de germinación y crecimiento. Se efectuó un análisis de varianza y regresión para los parámetros evaluados. El pH disminuyó y la CE incrementó al aumentar la concentración del extracto. La germinación fue estimulada en las concentraciones de extracto 0,5 y 1,0\%, e inhibida con 1,5 y 2,0\%. La altura de las plántulas, longitud de las radículas y los respectivos pesos secos de estos órganos disminuyeron con el incremento de la concentración del extracto. La relación altura de la plántula/longitud de la radícula aumentó con 0,5 y 1,0\% y disminuyó con 1,5 y $2,0 \%$.
\end{abstract}

Palabras clave: Cyperus rotundus, extractos acuosos, Sesamum indicum, alelopatía.

\begin{abstract}
The objective of this experiment was to determine the effects of foliage water extracts of purple nutsedge (Cyperus rotundus $L$.) on seed germination and seedling growth of sesame (Sesamum indicum L.) cv. Arapatol S-15. An extract was prepared with nutsedge foliage of 15 days at $15 \% \mathrm{w} / \mathrm{v}$. For the dilution, extracts of 0.0, 0.5, 1.0, 1.5 y $2.0 \% \mathrm{w} / \mathrm{v}$ were prepared, $\mathrm{pH}$ and electric conductivity (S.cm-1) were determined. Distilled water was uses as a control. Twenty five seeds were sowed in a double layer of absorbent paper on trays, covered with two leaves of absorbent paper. They were watered three times per day using foliage extracts. A randomized complete block design was used with the five extract concentrations (as above) and four replications. The traits were determined twelve days after sowing. An analysis of variance and regression were applied. The pH diminished and the electrical conductivity increased when the extract concentration was increased. The germination was stimulated by extracts concentrations of 0.5 and $1.0 \%$ and it was inhibited at 1.5 and $2.0 \%$. Seedling height, radicle length, shoot dry weight, radicle dry weight and the relationship between dry shoot weight/dry radicle weight decreased with an increase to the extract concentrations. Relationship between seedling height/radicle length increment up to the concentration of up to $1.0 \%$ and it descended at 1.5 and $2.0 \%$.
\end{abstract}

Key words: Cyperus rotundus, water extracts, Sesamum indicum, alellopathy.

1 Universidad de Oriente, Núcleo de Monagas, Escuela de Ingeniería Agronómica, Departamento de Agronomía, Campus "Los Guaritos”, Venezuela, Maturín E-mail: jalaynezg@yahoo.es y jmendezn@cantv.net.

Fecha de Recepción: 03 Mayo 2006

Fecha de Aceptación: 13 Junio 2006 


\section{INTRODUCCIÓN}

La alelopatía en un ecosistema manipulado como el que resulta de la práctica de la agricultura ha sido analizada sobre cuatro enfoques: el efecto de las malezas sobre los cultivos, los cultivos sobre las malezas, los cultivos sobre los cultivos y las malezas sobre las malezas. En relación al enfoque de la alelopatía desde el punto de vista de sus consecuencias negativas sobre un cultivo, ha sido comprobado que la ciperácea Cyperus rotundus L., conocida en nuestro país como corocillo o coquito, catalogada como la peor maleza del mundo por ser causante de problemas en más de noventa países del trópico y subtrópico, tiene efectos alelopáticos sobre diversos cultivos: tomate (Castro et al., 1983), cebada y limón volkameriano (Horowitz y Friedman, y Liendo, citados por Cárdenas, 1992) y lechuga, pimentón y jiló (Solanum gilo L.) (Guedes et al., 2002).

La infestación de áreas agrícolas por el corocillo es un serio problema, dado que esta planta invasora es de difícil control por presentar una rápida ocupación del suelo y alta capacidad de diseminación por medio de tubérculos, al mismo tiempo existen evidencias de que fenómenos de alelopatía pueden contribuir con su capacidad de establecimiento en agrosistemas. Un mayor conocimiento sobre los efectos alelopáticos de las sustancias liberadas por las hojas o raíces de esta planta en relación a la rotación de cultivos, manejo de residuos, prácticas de labranza y la implementación de control biológico de malezas, es necesario para establecer estrategias de manejo integrado orientadas a una mayor sustentabilidad de los sistemas de producción agrícola, en la búsqueda de alcanzar el deseado equilibrio ecológico. Por ejemplo, prácticas agrícolas como la siembra directa sobre rastrojo destinadas a una mejor conservación del agua y suelo no son aconsejables para ciertas combinaciones de cultivos por los efectos nocivos de las toxinas liberadas de los residuos en descomposición sobre la emergencia, crecimiento y productividad del cultivo siguiente. Sampietro (2002) hace referencia al efecto alelopático inhibitorio mostrado por residuos de corocillo en descomposición sobre el rendimiento del tomate, arroz, repollo, pepino, zanahoria, soya y algodón, indicándose como aleloquímicos a polifenoles y sesquiterpenos. Por otro lado, la identificación de los agentes alelopáticos de diversas plantas (e inclusive bacterias, hongos e insectos) auxilia a los fitomejoradores en la creación de genotipos más resistentes.

Considerando, por una parte, la importancia económica y social del cultivo de ajonjolí, cultivado básicamente por sus semillas comestibles, de las cuales se obtiene como producto principal aceite, considerado superior a otros aceites vegetales comúnmente usados en la alimentación humana, debido a su alta estabilidad y calidad (Ávila, 1999), y tomando por otro lado en cuenta los comprobados efectos alelopáticos sobre diversos cultivos del corocillo, el objetivo planteado, en el presente trabajo, es el de determinar los efectos de extractos acuosos del follaje del corocillo (Cyperus rotundus L.) sobre la germinación de semillas y el crecimiento de plántulas de ajonjolí (Sesamum indicum L.).

\section{MATERIALES Y MÉTODOS}

El presente trabajo se realizó en el Laboratorio de Semillas del Postgrado de Agricultura Tropical de la Universidad de Oriente, Maturín, Estado Monagas, Venezuela. Fue evaluada la acción de extractos acuosos foliares del corocillo, especie donadora, sobre la germinación de semillas y el crecimiento de plántulas de ajonjolí variedad Arapatol S-15, especie receptora.

\section{SIEMBRA}

Para la siembra en el laboratorio se emplearon bandejas de aluminio (17,5 $\mathrm{cm}$ largo, $11,0 \mathrm{~cm}$ ancho y $2,5 \mathrm{~cm}$ alto) desinfectadas con cloro comercial (hipoclorito de sodio 5,25\%) y cubiertas con una capa de dos hojas de papel absorbente, sobre las que se colocaron 25 semillas/bandeja disponiendo así de 100 semillas por tratamiento en función de cuatro repeticiones. Las semillas fueron dejadas al descubierto (sin cobertura de capa de papel) por mostrar en una prueba preliminar su incapacidad de abrirse paso a través del papel. Se realizaron tres riegos diarios (en la mañana, a mediodía y en la tarde), humedeciendo el papel de las bandejas mediante un aspersor manual con los extractos de los tratamientos. La cosecha de las plántulas se efectuó a los 12 días después de la siembra.

\section{PREPARACIÓN DE LOS EXTRACTOS ACUOSOS}

Follaje de plantas de corocillo de unos 15 días de edad fue recolectado en una siembra de algodón 
(Gossypium hirsutum L.) en las parcelas experimentales del Campus Universitario "Los Guaritos", secado a temperatura ambiente por $24 \mathrm{~h}$, y después en estufa $\left(72 \mathrm{~h}, 50{ }^{\circ} \mathrm{C}\right)$. Una vez seco, se preparó un extracto al $15 \% \mathrm{p} / \mathrm{v}$, para lo cual el follaje fue cortado en trozos no mayores de $3 \mathrm{~cm}$ y licuado en agua sin llegar a pulverizar (aprox. $10 \mathrm{~s}$.). La preparación así obtenida se dejó en reposo por 48 $\mathrm{h}$ en recipientes de vidrio tapados. Posteriormente, fue separado el líquido de la parte sólida a través de un proceso de filtrado (papel filtro Whatman 1) y a partir de este extracto se obtuvieron por dilución extractos al 0,$5 ; 1,0 ; 1,5$ y $2,0 \%$ p/v. A cada uno de ellos se le determinó el $\mathrm{pH}$ y la conductividad eléctrica $\left(\mathrm{S} . \mathrm{cm}^{-1}\right)$. Como tratamiento control se empleó agua corriente.

\section{DISEÑO EXPERIMENTAL}

Se utilizó el diseño estadístico de bloques al azar. Se estudió el efecto de cinco concentraciones $(0 ; 0,5 ; 1,0 ; 1,5$ y $2,0 \% \mathrm{p} / \mathrm{v})$ de extracto acuoso foliar de corocillo sobre el ajonjolí; se emplearon cuatro repeticiones.

\section{VARIABLES MEDIDAS}

A cada planta se le evaluaron a los 12 días después de la siembra los parámetros de Germinación: porcentaje de germinación (\%) y Crecimiento: altura de la plántula $(\mathrm{cm})$, longitud de la radícula $(\mathrm{cm})$, pesos secos del vástago y de la radícula $(\mathrm{g})$, secados en estufa a $70^{\circ} \mathrm{C}$ por $72 \mathrm{~h}$, y las relaciones altura de la plántula/longitud de la radícula y peso seco del vástago/peso seco de la radícula.

\section{ANÁLISIS ESTADÍSTICO}

Los resultados de los parámetros fueron evaluados mediante análisis de varianza y de regresión. La transformación de los datos del porcentaje de germinación se realizó mediante la fórmula arcoseno $\sqrt{\frac{\left(x+\frac{3}{8}\right)}{\left(n+\frac{3}{4}\right)}}$ en los casos en que fue necesario transformar los datos de los caracteres se utilizaron las fórmulas $\sqrt{(x+0,5)}$ y $(\sqrt{x}+\sqrt{(x+1)})$. Se efectuó un análisis de regresión al $\mathrm{pH}$ y la conductividad eléctrica de los extractos acuosos foliares del corocillo en una sola repetición.

\section{RESULTADOS Y DISCUSIÓN}

\section{ANÁLISIS DE PH Y CONDUCTIVIDAD ELÉCTRICA DE LOS EXTRACTOS FOLIARES}

Los resultados de los análisis de regresión para el potencial hidrogénico $(\mathrm{pH})$ y la conductividad eléctrica (CE) de los extractos acuosos del follaje del corocillo se muestran en el Cuadro 1.

En el Cuadro 2 se presentan los análisis de regresión para porcentaje de germinación (PG), alturas de las plántulas (AP), longitud de las radículas (LR) y relación altura de la plántula/longitud de la radícula (RAP/LR).

En el Cuadro 3 se muestran los análisis de regresión para los pesos secos de los vástagos (PSV), pesos

Cuadro 1

Análisis de regresión para el pH y la conductividad eléctrica de los extractos acuosos foliares de corocillo (Cyperus rotundus $\mathrm{L}$.)

\begin{tabular}{|l|c|c|c|c|c|}
\hline \multirow{2}{*}{ Fuente de Variación } & \multirow{2}{*}{ Grados de Libertad } & \multicolumn{3}{|c|}{ Cuadrado Medio } \\
\cline { 3 - 6 } & & \multicolumn{2}{|c|}{$\mathbf{p H}$} & \multicolumn{2}{|c|}{ Conductividad eléctrica } \\
\hline Regresión & 1 & 0,00841 & $*$ & $\begin{array}{l}1,52100 \\
0,03667\end{array}$ & $* *$ \\
Residual & 3 & 0,00077 & & & \\
\hline Total & 4 & & & & \\
\hline
\end{tabular}

$*$ : Significativo $(\mathrm{p} \leq 0,05) * *$ : Significativo $(\mathrm{p} \leq 0,01)$. 
Cuadro 2

Análisis de regresión para porcentaje de germinación (PG), altura de la plántula (AP) (cm), longitud de la radícula $(\mathrm{LR})(\mathrm{cm})$ y relación altura de la plántula/longitud de la radícula $(\mathrm{RAP} / \mathrm{LR})$ en ajonjolí (Sesamum indicum L.) cv. Arapatol S-15, bajo diferentes concentraciones de extractos acuosos del follaje de corocillo (Cyperus rotundus $\mathbf{L}$.), en condiciones de laboratorio

\begin{tabular}{|c|c|c|c|c|c|c|c|c|c|}
\hline \multirow{3}{*}{$\begin{array}{l}\text { Fuente de Variación } \\
\text { Repetición }\end{array}$} & \multirow{3}{*}{$\begin{array}{c}\text { Grados de Libertad } \\
3\end{array}$} & \multicolumn{8}{|c|}{ Cuadrados medios } \\
\hline & & \multicolumn{2}{|c|}{ PG } & \multicolumn{2}{|c|}{$\mathbf{A P}$} & \multicolumn{2}{|c|}{ LR } & \multicolumn{2}{|c|}{ RAP/LR } \\
\hline & & 0,020 & ns & 0,247 & ns & 0,059 & $\mathrm{~ns}$ & 0,604 & $\mathrm{~ns}$ \\
\hline Concentración & 4 & 0,620 & $*$ & 1,922 & $*$ & 1,429 & $*$ & 1,235 & $*$ \\
\hline Reg. Lineal & 1 & 0,793 & $*$ & 7,590 & $*$ & 5,446 & $*$ & 0,276 & $\mathrm{~ns}$ \\
\hline Reg. Cuadrática & 1 & 0,767 & $*$ & 0,010 & $\mathrm{~ns}$ & 0,249 & $*$ & 3,401 & * \\
\hline Reg. Cúbica & 1 & 0,919 & $*$ & 0,085 & ns & 0,002 & $\mathrm{~ns}$ & 0,174 & $\mathrm{~ns}$ \\
\hline Efecto Residual & 1 & 0,001 & ns & 0,002 & ns & 0,018 & ns & 1,088 & $\mathrm{~ns}$ \\
\hline Error Experimental & 12 & 0,158 & & 0,142 & & 0,045 & & 0,357 & \\
\hline Total & 19 & & & & & & & & \\
\hline C. V. $(\%)$ & & 3,18 & & 24,24 & & 16,20 & & 39,03 & \\
\hline
\end{tabular}

*: Significativo $(\mathrm{p} \leq 0,05) \mathrm{ns}$ : No Significativo $(\mathrm{p} \leq 0,05)$.

\section{Cuadro 3}

Análisis de regresión para peso seco del vástago (PSV) (g), peso seco de la radícula (PSR) (g) y relación peso seco del vástago/peso seco de la radícula (RPSV/PSR) en ajonjolí (Sesamum indicum $\mathbf{L}$.) cv. Arapatol S-15, bajo diferentes concentraciones de extractos acuosos del follaje de corocillo (Cyperus rotundus $\mathbf{L}$.), en condiciones de laboratorio

\begin{tabular}{|l|c|c|c|c|c|c|c|}
\hline \multirow{2}{*}{ Fuente de Variación } & \multirow{2}{*}{ Grados de Libertad } & \multicolumn{5}{|c|}{ Cuadrados Medios } \\
\cline { 3 - 8 } & 3 & \multicolumn{2}{|c|}{ PSV } & \multicolumn{2}{|c|}{ PSR } & \multicolumn{3}{|c|}{ RPSV/PSR } \\
\hline Repetición & 4 & 0,000083 & $\mathrm{~ns}$ & 0,000029 & $\mathrm{~ns}$ & 0,3240 & $\mathrm{~ns}$ \\
Concentración & 1 & 0,001270 & $*$ & 0,000420 & $*$ & 3,7880 & $*$ \\
Reg. Lineal & 1 & 0,004494 & $*$ & 0,001488 & $*$ & 11,9460 & $*$ \\
Reg. Cuadrática & 1 & 0,000005 & $\mathrm{~ns}$ & 0,000003 & $\mathrm{~ns}$ & 0,2730 & $\mathrm{~ns}$ \\
Reg. Cúbica & 1 & 0,000292 & $\mathrm{~ns}$ & 0,000116 & $\mathrm{~ns}$ & 1,3840 & $\mathrm{~ns}$ \\
Efecto Residual & 12 & 0,000290 & $\mathrm{~ns}$ & 0,000074 & $\mathrm{~ns}$ & 1,5500 & $\mathrm{~ns}$ \\
Error Experimental & 19 & 0,000081 & & 0,000026 & & 0,3570 & \\
\hline Total & 1 & & & & & & \\
\hline C. V. $(\%)$ & & 0,88 & & 0,50 & & 27,86 & \\
\hline
\end{tabular}

*: Significativo $(\mathrm{p} \leq 0,05) \mathrm{ns}$ : No Significativo $(\mathrm{p} \leq 0,05)$.

secos de las radículas (PSR) y relación peso seco del vástago/peso seco de la radícula (RPSV/PSR).

En la Figura 1 se muestran los análisis de regresión para los valores de $\mathrm{pH}$ y $\mathrm{CE}$ de los extractos acuosos del follaje del corocillo. Se observa una tendencia a disminuir gradualmente el $\mathrm{pH}$ y a aumentar la CE conforme se incrementa la concentración. Los valores de $\mathrm{pH}$ oscilaron entre 6,64 y 6,50 , mientras que los de CE estuvieron entre 0,10 y $1,70 \mathrm{~S} . \mathrm{cm}^{-1}$. 


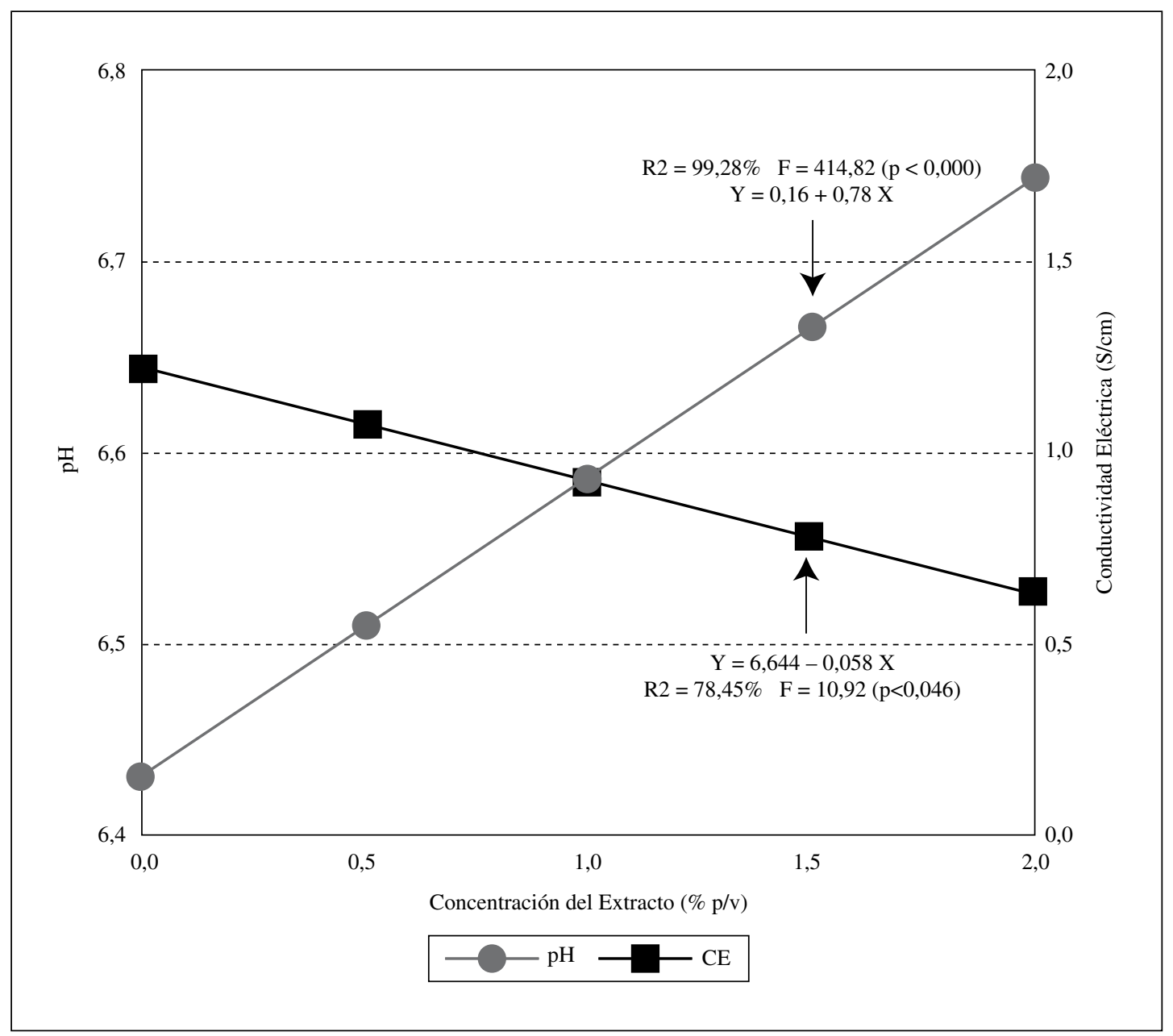

Figura 1. Análisis de regresión para valores del potencial hidrogénico $(\mathrm{pH})$ y conductividad eléctrica $(\mathrm{CE})$ de los extractos acuosos del follaje del corocillo (Cyperus rotundus L.), utilizados en el ensayo con ajonjolí (Sesamum indicum L.)

Los valores de $\mathrm{pH}$ presentaron muy poca variación entre el testigo y las concentraciones de extractos acuosos foliares empleadas, por lo que se presume que no existió efecto de este parámetro sobre la germinación y el crecimiento de las plántulas. No ocurrió lo mismo con la $\mathrm{CE}$, la cual incrementó con el aumento de la concentración de los extractos, sugiriendo altas concentraciones de sales o sustancias químicas liberadas a partir de las hojas de corocillo. Por lo tanto, adicionalmente a los posibles compuestos activos del corocillo, la alta cantidad de sales o de concentración de sustancias químicas posiblemente causó un estrés osmótico durante la germinación y el crecimiento de las plántulas. Tal efecto osmoticante es común de apreciar cuando se incrementa la concentración de soluto en una solución, como lo señalan Méndez et al. (2002a y 2002b), quienes efectuaron dos ensayos en condiciones de laboratorio, en los que determinaron el efecto del cloruro de sodio y del sulfato de sodio, respectivamente, con cinco potenciales osmóticos ( $0,-3,-6,-9$ y -12 bares) sobre la germinación de semillas y crecimiento de plántulas de los híbridos comerciales de maíz Cargill 633, Himeca 2003 y Pioneer 3031, y al realizar las evaluaciones a los 12 días después de la siembra, encontraron que en el ensayo con cloruro de sodio el porcentaje de germinación se incrementó $8,41 \%$ a -3 bares, para luego disminuir con incrementos del potencial, la germinación se redujo $84,69 \%$ a -12 bares; las mayores reducciones de la altura de la plántula y la longitud de radícula ocurrieron a -9 y -12 bares con 99,87 y $96,99 \%$, respectivamente 
para la altura de la plántula y 97,92 y 95,20\% para la longitud de la radícula. En el ensayo con sulfato de sodio encontraron que el porcentaje de germinación se incrementó 9,45\% a -3 bares, para luego disminuir con incrementos del potencial, la germinación se redujo 83,72 y 73,28\% a -9 y -12 bares, respectivamente. La mayor reducción de la altura de la plántula ocurrió a -6 y -9 bares con 97,54 y $98,18 \%$, respectivamente. Las mayores reducciones en la longitud de la radícula ocurrieron a -9 y -12 bares en los cultivares Cargill 633 e Himeca 2003 y a -6 y -9 bares en Pioneer 3031.

Por otra parte, efectos sobre el pH y la CE por el incremento de la concentración en soluciones preparadas con extractos de corocillo han sido señalados por Guedes et al. (2002), quienes trabajaron con extractos de Cyperus rotundus L. y señalan que al evaluar el $\mathrm{pH}$ y la $\mathrm{CE}$ en los extractos en estudio, el primero fluctuó entre 6,1 y 6,5 (valores muy cercanos a los encontrados en este trabajo, donde el pH osciló entre 6,64 y 6,5) y según las reglas de la International Seed Testing Association, los valores de $\mathrm{pH}$ entre 6,0 y 7,5 son considerados ideales para la germinación de la mayoría de las especies vegetales, lo que sugiere que los valores de $\mathrm{pH}$ de los extractos poco o nada interfirieron en la germinación de las especies estudiadas. En relación a la $\mathrm{CE}$, los autores señalan también que los valores obtenidos en los extractos vegetales de la parte aérea variaron entre 1,58 y 7,47 S.cm-1, siendo investigado el efecto del potencial osmótico sobre el porcentaje de germinación para discriminar entre el efecto inhibitorio de este factor y el correspondiente a las sustancias del corocillo, y observaron que aun cuando existió un efecto de regresión significativo para el potencial osmótico en razón de las concentraciones de los extractos también se presentó efecto por los compuestos de corocillo. En el presente trabajo el rango de los valores de CE $\left(0,10\right.$ a 4,90 S.cm $\left.{ }^{-1}\right)$ se ubicó por debajo del valor observado para las concentraciones en las cuales se presentó reducción sobre la germinación en el trabajo de Guedes et al. (concentración de los extractos 4 y $6 \%, \mathrm{CE}=6,74$ y 7,47 S.cm ${ }^{-1}$, respectivamente), lo que parece indicar la no existencia de relación entre el efecto reductor apreciado sobre la germinación y crecimiento producido por las sustancias químicas del corocillo presentes en los extractos en este trabajo y la CE, claro está que por tratarse de diferentes especies se torna necesaria una prueba que afirme esta observación.

\section{GERMINACIÓN}

\section{Porcentaje de germinación}

Se presentaron diferencias significativas únicamente para las fuentes de variación concentración, regresión lineal, cuadrática y cúbica (Cuadro 1). En la Figura 2 se observa el análisis de regresión para el porcentaje de germinación de semillas de ajonjolí variedad Arapatol S-15, bajo las diferentes concentraciones de extractos acuosos del follaje del corocillo. Se observa un incremento en la germinación con respecto al testigo en la concentración de 0,5 y $1,0 \%$, para posteriormente disminuir hasta alcanzar la concentración de $1,5 \%$, momento a partir del cual tiende a estabilizarse; la respuesta fue cúbica.

\section{CRECIMIENTO}

\section{Altura de la plántula $(\mathrm{cm})$}

Se presentaron diferencias significativas solo para las fuentes de variación concentración y regresión lineal (Cuadro 1). En la Figura 3 se observa el análisis de regresión para la altura de las plántulas de ajonjolí variedad Arapatol S-15, bajo las diferentes concentraciones de extractos acuosos del follaje del corocillo. Hubo una respuesta lineal; se aprecia una tendencia a disminuir el carácter en la medida en que se incrementa la concentración de extracto.

\section{Longitud de la radícula $(\mathrm{cm})$}

Se apreciaron diferencias significativas únicamente para las fuentes de variación concentración, regresión lineal y cuadrática (Cuadro 1). En la Figura 4 se observa el análisis de regresión para la longitud de la radícula de las plántulas de ajonjolí variedad Arapatol $\mathrm{S}-15$, bajo las diferentes concentraciones de extractos acuosos del follaje del corocillo. La respuesta fue cuadrática; se observó que a medida que se incrementó la concentración del extracto la longitud de la radícula se redujo, y que el mayor efecto inhibidor se presentó en las concentraciones mayores 1 y $2 \%$.

\section{Peso seco del vástago (g)}

Se presentaron diferencias significativas solo en las fuentes de variación concentración y regresión lineal (Cuadro 2). En la Figura 5 se observa el análisis de regresión para el peso seco del vástago de las 


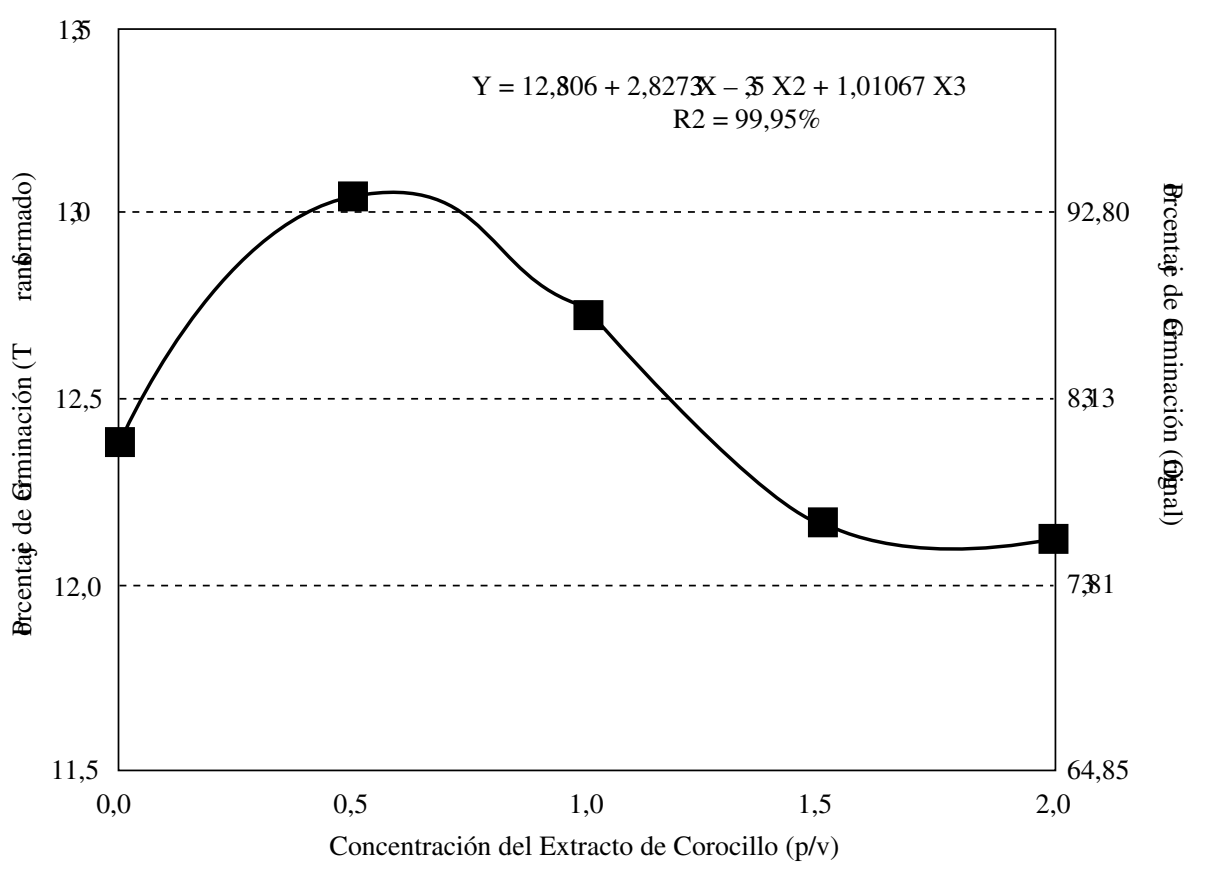

Figura 2. Análisis de regresión para porcentaje de germinación de semillas de ajonjolí (Sesamum indicum L.) cv. Arapatol S-15, bajo diferentes concentraciones de extractos acuosos del follaje de corocillo (Cyperus rotundus L.), en condiciones de laboratorio.
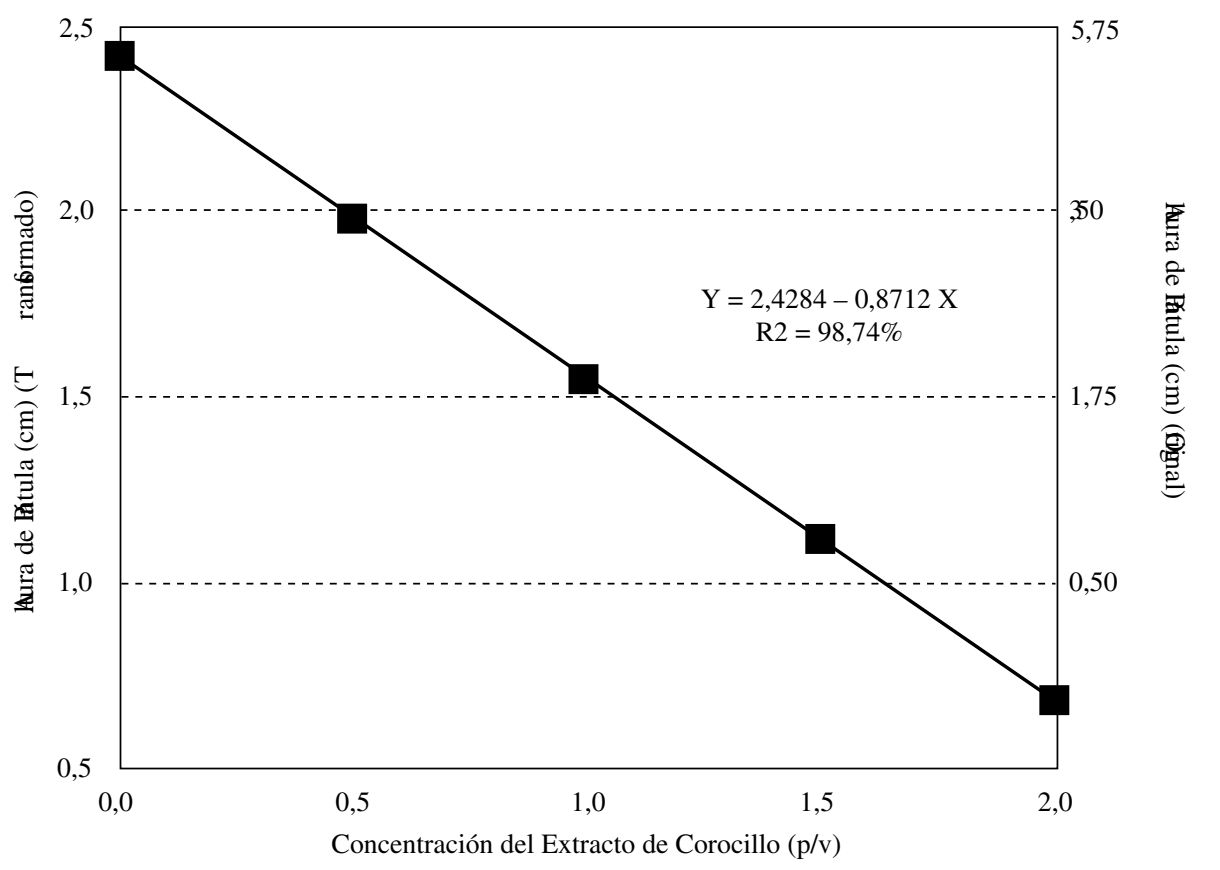

Figura 3. Análisis de regresión para la altura de plántulas de ajonjolí (Sesamum indicum L.) cv. Arapatol S-15, bajo diferentes concentraciones de extractos acuosos del follaje de corocillo (Cyperus rotundus L.), en condiciones de laboratorio. 


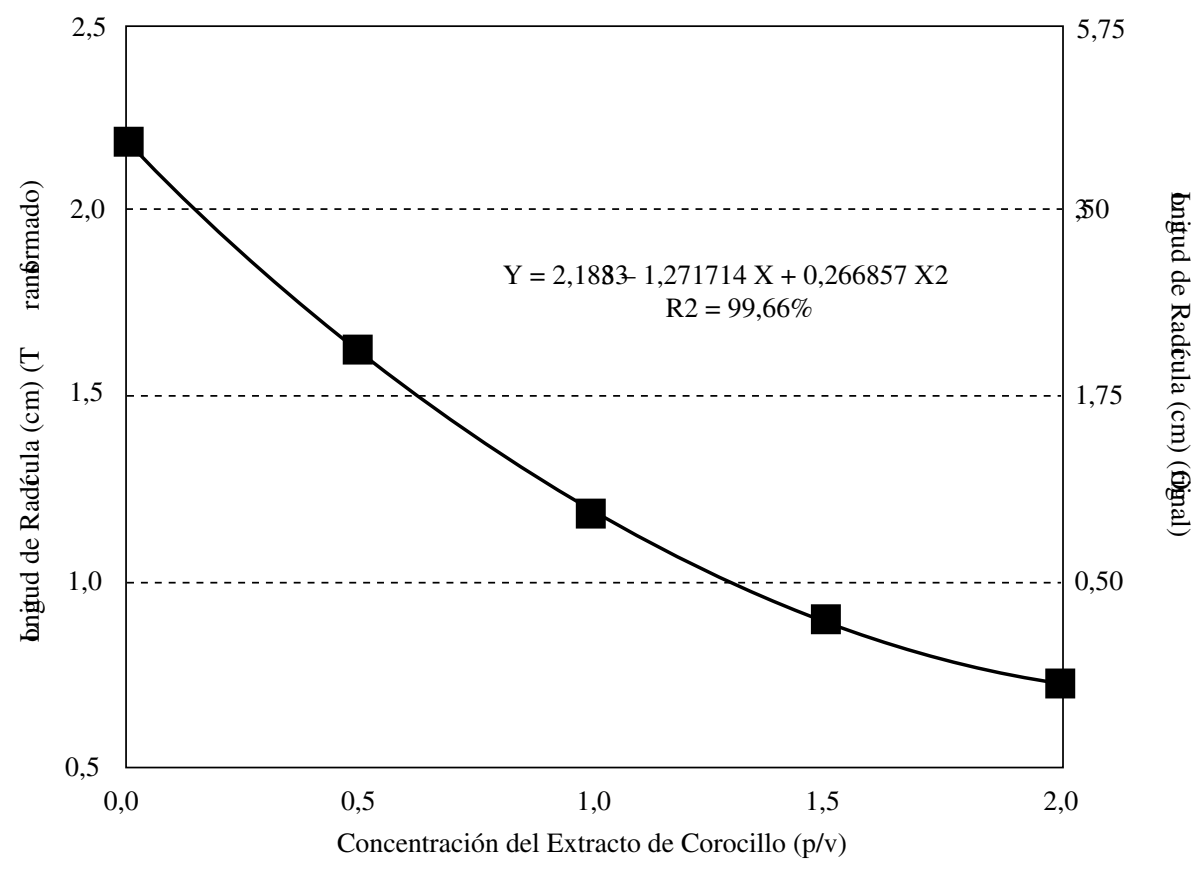

Figura 4. Análisis de regresión para longitud de la radícula de plántulas de ajonjolí (Sesamum indicum L.) cv. Arapatol S-15, bajo diferentes concentraciones de extractos acuosos del follaje de corocillo (Cyperus rotundus L.), en condiciones de laboratorio.

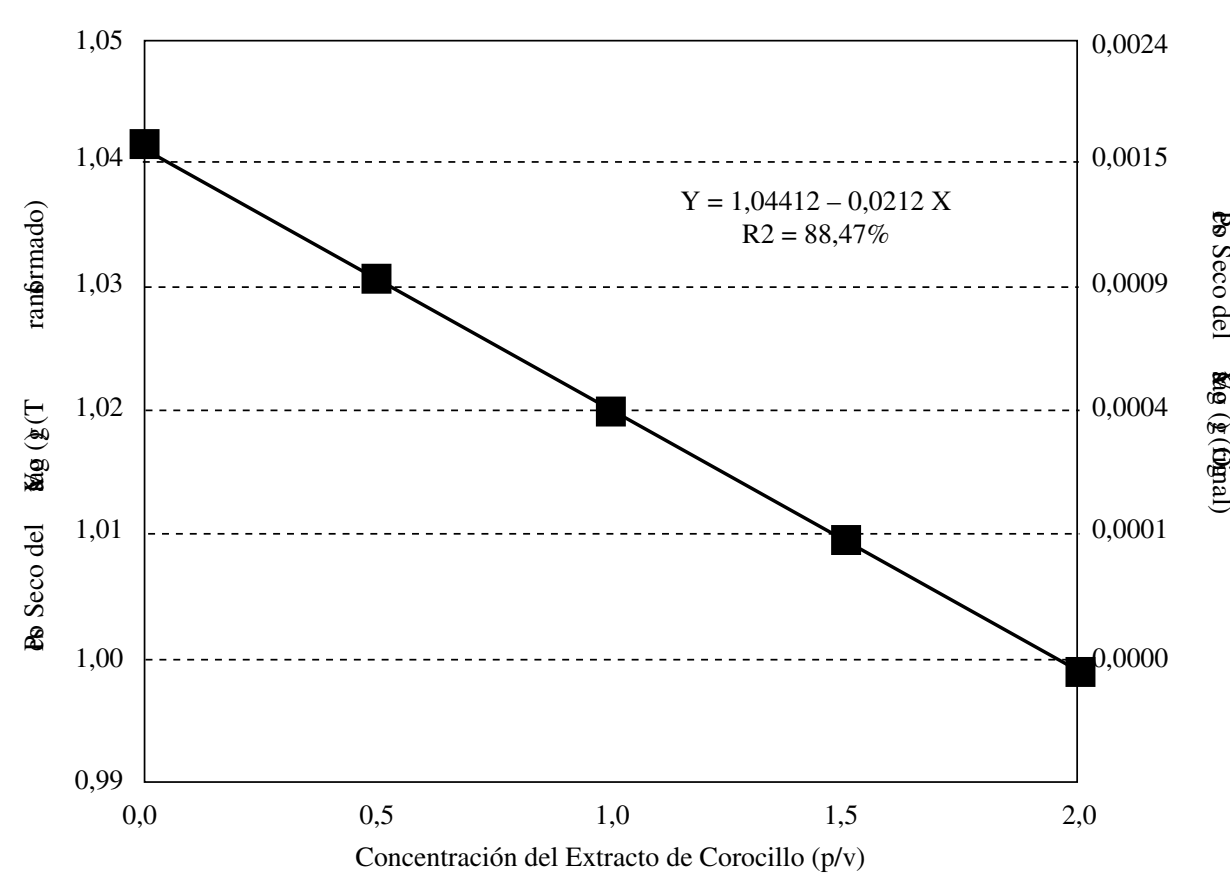

Figura 5. Análisis de regresión para el peso seco del vástago de plántulas de ajonjolí (Sesamum indicum L.) cv. Arapatol S-15, bajo diferentes concentraciones de extractos acuosos del follaje de corocillo (Cyperus rotundus L.), en condiciones de laboratorio. 
plántulas de ajonjolí variedad Arapatol S-15 bajo las diferentes concentraciones de extractos acuosos del follaje del corocillo. Se apreció disminuciones progresivas (lineales) de este carácter por efecto del incremento de la concentración de extracto.

\section{Peso seco de la radícula $(g)$}

Únicamente se presentaron diferencias significativas para las fuentes de variación concentración y regresión lineal (Cuadro 2). En la Figura 6 se observa el análisis de regresión para el peso seco de las radículas de las plántulas de ajonjolí variedad Arapatol S-15, bajo las diferentes concentraciones de extractos acuosos del follaje del corocillo. La respuesta fue lineal, incrementos en la concentración de extracto redujeron proporcionalmente el peso seco de la radícula.

\section{Relación altura de la plántula/longitud de la radícula}

Previo al análisis, a aquellos datos que presentaron valores de cero se les colocó arbitrariamente el valor de 1. Se presentaron diferencias significativas solo para las fuentes de variación concentración y regresión cuadrática (Cuadro 1). En la Figura 7 se observa el análisis de regresión para relación altura de la plántula/longitud de la radícula de las plántulas de ajonjolí variedad Arapatol S-15, bajo las diferentes concentraciones de extractos acuosos del follaje del corocillo. Se observó un incremento en la relación cuando la concentración de extracto aumentó hasta un 1\%; las concentraciones mayores redujeron el valor de la relación, la respuesta fue cuadrática.

\section{Relación peso seco del vástago/peso seco de la radícula}

Previo al análisis, a aquellos datos que presentaron valores de cero se les colocó arbitrariamente el valor de 1 (Cuadro 2). Se presentaron diferencias significativas solo en las fuentes de variación concentración y regresión lineal. En la Figura 8 se observa el análisis de regresión para relación peso seco del vástago/peso seco de la radícula de

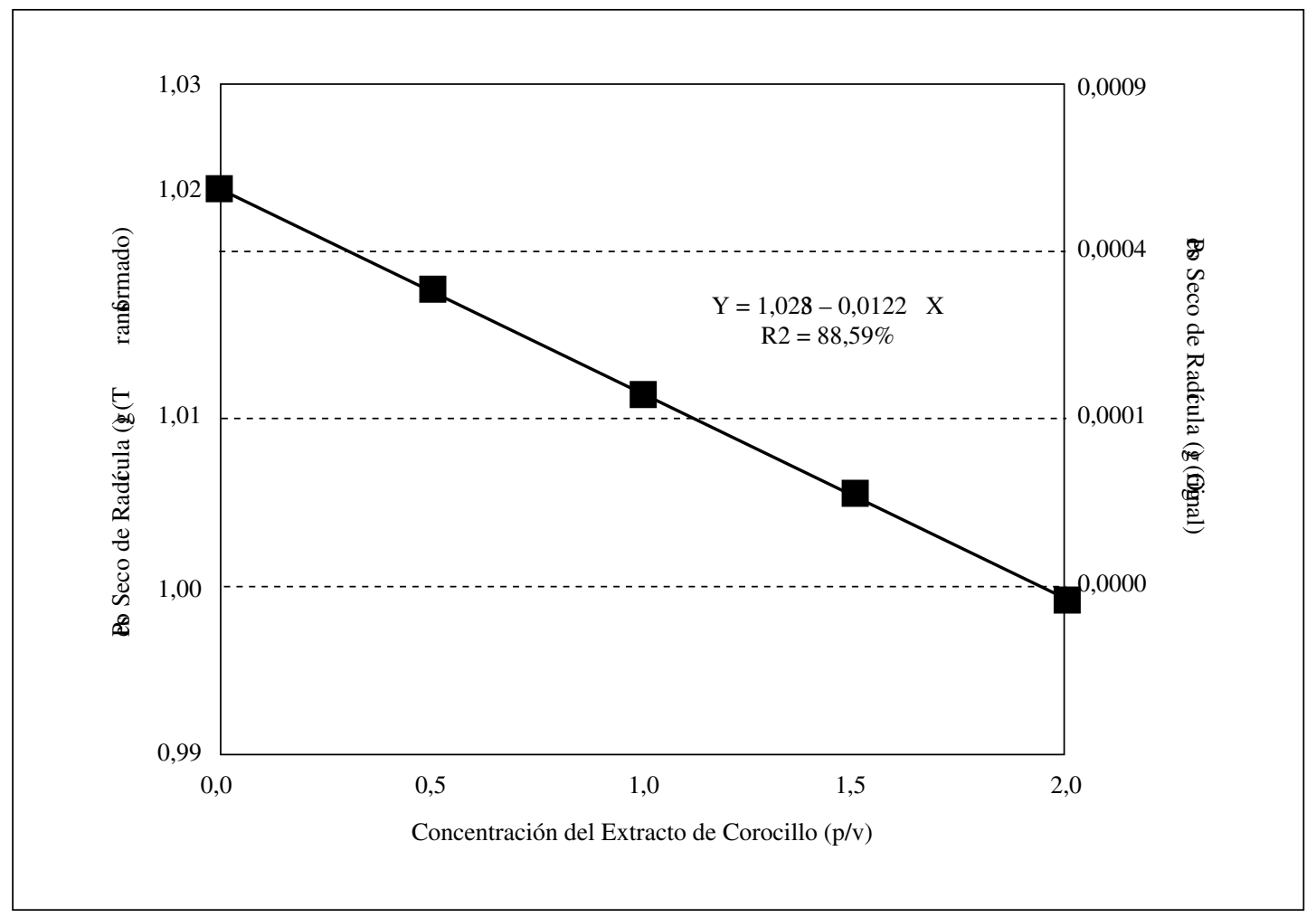

Figura 6. Análisis de regresión para el peso seco de la radícula de plántulas de ajonjolí (Sesamum indicum L.) cv. Arapatol S-15, bajo diferentes concentraciones de extractos acuosos del follaje de corocillo (Cyperus rotundus L.), en condiciones de laboratorio. 


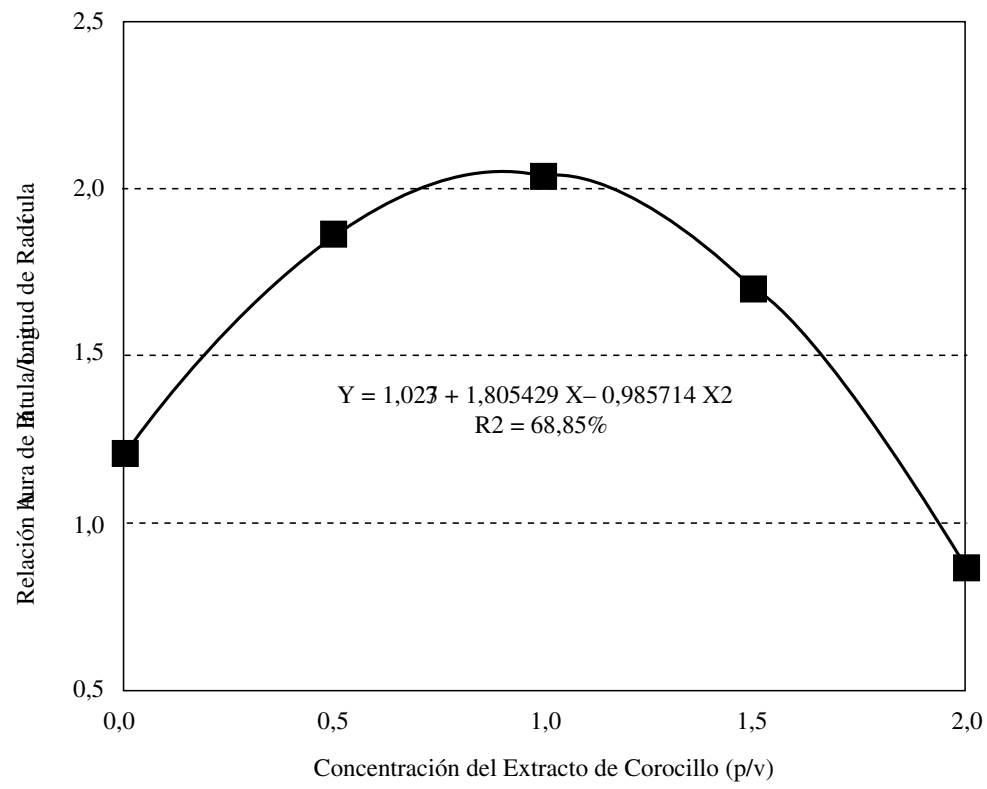

Figura 7. Análisis de regresión para la relación altura de la plántula/longitud de la radícula de plántulas de ajonjolí (Sesamum indicum L.) cv. Arapatol S-15, bajo diferentes concentraciones de extractos acuosos del follaje de corocillo (Cyperus rotundus L.), en condiciones de laboratorio.

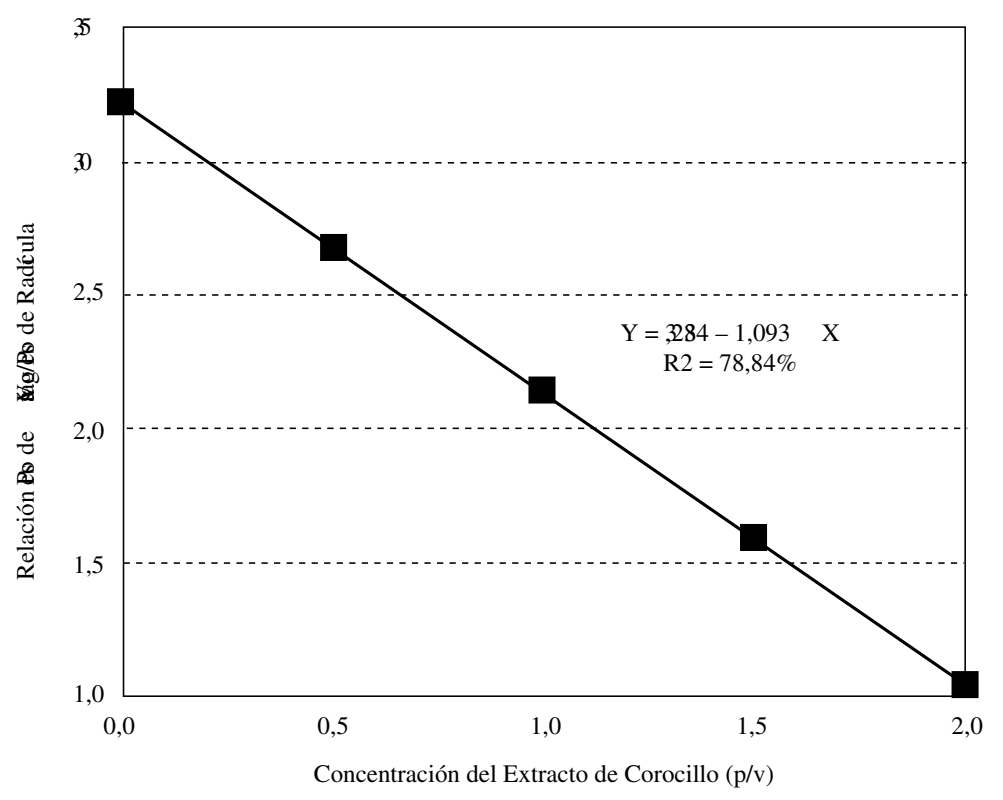

Figura 8. Análisis de regresión para la relación peso seco del vástago/peso seco de la radícula de plántulas de ajonjolí (Sesamum indicum L.) cv. Arapatol S-15, bajo diferentes concentraciones de extractos acuosos del follaje de corocillo (Cyperus rotundus L.), en condiciones de laboratorio. 
las plántulas de ajonjolí variedad Arapatol S-15, bajo las diferentes concentraciones de extractos acuosos del follaje del corocillo. La respuesta fue lineal, la relación disminuye en la medida en que se incrementa la concentración.

\section{Efecto de los extractos sobre la germinación}

Se apreció un estímulo en la germinación respecto al testigo en las concentraciones más bajas, con tendencia a disminuir con el incremento de la concentración de extracto foliar hasta tornarse inhibidor en relación al testigo en las concentraciones más altas. Resultados similares a los obtenidos en este ensayo en la germinación se han señalado por efecto de: a) Compuestos del corocillo sobre la germinación de diversos cultivos: Guedes et al. (2002) apreciaron estímulo en el porcentaje de germinación en lechuga en relación al control a concentraciones de 1 y $2 \%$ de extractos de la parte aérea y extractos de la parte subterránea, sin embargo, a 4 y $6 \%$ los efectos fueron inhibitorios; inhibición en la germinación del pimentón por extractos de la parte aérea y estímulos en la misma por los extractos de la parte subterránea en todas las concentraciones; reducción en el porcentaje de germinación en jiló (Solanum gilo L.) por los extractos de la parte aérea, en las concentraciones intermedias y tendencia de recuperación a concentración de $6 \%$, los extractos de la parte subterránea inhibieron la germinación a concentraciones entre 1 y $4 \%$, pero la concentración de $6 \%$ resultó estimulante; b) Extractos de otras malezas sobre cultivos: Castro et al. (1983), inhibición total de las semillas de tomate con el extracto puro de rizomas de Sorghum halepense, y disminuciones de la germinación sin inhibición con el extracto al $50 \%$; inhibición de la germinación en tomate con extractos acuosos del sistema radicular de Cynodon dactylon L.; inhibición de la germinación en tomate con extracto de raíces de Cannavalia ensiformis; inhibición mayor de la germinación en tomate por las hojas de Brassica napus respecto a la producida por las raíces; Arnaude et al. (2001), inhibición de la germinación de semillas de lechuga (Lactuca sativa) por extractos acuosos y orgánicos de Pteridium aquilinum (helecho macho) en un $50 \%$ y en un $63 \%$, respectivamente; c) Extractos de cultivos sobre malezas: Ahn y Chung (2000), inhibición de la germinación de plántulas de Echinochloa crusgalli por los extractos de cáscara de arroz.
En relación al efecto inhibitorio observado sobre la germinación, queda la duda en este ensayo sobre si las semillas perdieron su viabilidad o tan solo su germinación se vio retrasada. Al respecto, Petersen et al. (2001) evaluaron el potencial alelopático de isotiocianatos (ITC) liberados por el nabo (Brassica rapa (L.) var. rapa ssp. olifera (DC.) Metzg. cv. Perko) aplicado como cobertura del suelo sobre varias especies de malezas y observaron que las bajas concentraciones de isotiocianatos retrasaron la germinación, pero las semillas no germinadas fueron aun viables, señalando que consecuentemente las bajas concentraciones de ITC pueden inducir una latencia secundaria en las semillas. Altas concentraciones de ITC pueden penetrar en las semillas en grandes cantidades y reaccionar con las enzimas, perdiendo estas su viabilidad, porque las reacciones con las enzimas son irreversibles.

Por otro lado, el número de plántulas disminuyó en el tiempo con el incremento de la concentración de extracto (valores no evaluados), por lo que una vez ocurrida la germinación, la sobrevivencia de las plántulas es un factor de importancia a ser considerado.

\section{Efecto de los extractos sobre el crecimiento}

Los valores de los parámetros de crecimiento disminuyeron conforme incrementó la concentración de extracto acuoso foliar. La altura de las plántulas, longitud de las radículas y los respectivos pesos secos de estos órganos disminuyeron con el incremento de la concentración; sin embargo, en la relación altura de la plántula/longitud de la radícula se observó un estímulo respecto al control en las concentraciones iniciales y un efecto inhibitorio en la mayor concentración, mientras que en la relación peso seco del vástago/peso seco de la radícula los valores disminuyeron progresivamente con los incrementos de la concentración del extracto. Se han reportado efectos alelopáticos sobre el ajonjolí. Borghetti et al. (2005) investigaron las propiedades alelopáticas de cinco especies en el Cerrado brasileño sobre el ajonjolí utilizando extractos acuosos de diferentes concentraciones y encontraron que los extractos foliares de Qualea parviflora a 0,5\% redujeron en $60 \%$ el crecimiento radicular cuando se comparó con el control, pero los extractos al $2 \%$ y por encima fueron necesarios para inhibir significativamente el crecimiento del vástago de las plántulas de ajonjolí; los extractos de Eugenia dysenterica al $1 \%$ 
redujeron en más de $80 \%$ el crecimiento radicular pero no tuvieron un efecto significativo sobre los vástagos; los extractos foliares de Trembleya parviflora y Campomanesia adamantinum al $1 \%$ inhibieron el crecimiento de la radícula en más del $50 \%$ cuando se comparó con el control. Por otra parte, los extractos de C. adamantinum hasta el $2 \%$ no afectaron el crecimiento del vástago, mientras los extractos de $T$. parviflora hasta $2 \%$ redujeron el crecimiento del vástago en $15 \%$; finalmente, los extractos de Solanum lycocarpum inhibieron el crecimiento radicular en más de $50 \%$ a una concentración tan baja como 1\%, pero el crecimiento del vástago no fue afectado a concentraciones hasta $3 \%$. Los efectos de los extractos foliares tanto de $S$. lycocarpum como de $Q$. parviflora sobre el crecimiento de la radícula mostraron una relación dosis-respuesta; para ambas especies el crecimiento del vástago fue inhibido solo a las concentraciones más altas $(2-5 \%)$.

Jerônimo et al. (2005) estudiaron los efectos de S. lycocarpum sobre el crecimiento de la radícula y del vástago y la síntesis de proteínas de plántulas de ajonjolí y encontraron que los extractos foliares significativamente redujeron el crecimiento de la radícula e inhibieron la diferenciación de las raíces laterales y los pelos radícales en plántulas de ajonjolí después de dos a cinco días de incubación; las raíces fueron más afectadas que los vástagos, después de cinco días, el crecimiento radícular se redujo en aproximadamente $80 \%$ con el extracto al $1 \%$, pero el crecimiento del vástago no fue significativamente afectado hasta la concentración de 3\%. Sin importar los efectos de los extractos sobre el crecimiento del vástago, no se observó ninguna anormalidad en la morfología del vástago de las plántulas tratadas y los cotiledones se expandieron y los hipocotilos se tornaron verde similarmente a las plántulas control, por lo tanto, no se conoció si la reducción del crecimiento del vástago fue un efecto directo de los extractos sobre los vástagos o simplemente una consecuencia de los efectos de los extractos sobre el metabolismo de las raíces. Oliveira et al. (2004) indicaron que para el ajonjolí, las raíces son más susceptibles a los extractos foliares que los vástagos, pero los extractos de $S$. lycocarpum no afectaron la germinación, pero incrementaron el tiempo promedio de germinación de una manera dependiente de la dosis.

La inhibición o el estímulo del crecimiento de un órgano son comúnmente observados ante el tratamiento de plantas con extractos de otras plantas. Se han señalado: a) Efectos del corocillo sobre cultivos: Castro et al. (1983) observaron disminuciones pronunciadas del crecimiento de la radícula y el hipocótilo del tomate (Lycopersicum esculentum Mill.); Meissner et al. (1982) encontraron que el extracto no diluido del tubérculo impidió la elongación de la radícula de pepino, rábano, cebolla y tomate; b) Efectos de otras malezas sobre cultivos: Miquilena y Vicente (2001), efectos estimulatorios en la longitud radical en tomate ( $L$. esculentum Mill) con los exudados radicales de Trianthema portulacastrum L. recolectados 15 días después de la germinación de la maleza, e igualmente con los de Amaranthus dubius Mart., Echinochloa colona (L.). Link y Trianthema portulacastrum L., recolectados al inicio de floración; Zambrano y Vicente (2001), inhibición de la altura y la longitud radical en Oryza sativa y $L$. sativa, en algunos tratamientos, y estímulo para la longitud radical en $O$. sativa, I. rugosum y en L. sativa, en otros, por efecto de exudados radicales y lavados foliares de Cyperus iria L.; c) Efectos de malezas sobre malezas: Zambrano y Vicente (2001), inhibición de la altura y la longitud radical en Echinochloa colona, Ischaemum rugoso, en algunos tratamientos, y estímulo para la altura en I. rugosum, en otros, por efecto de exudados radicales y lavados foliares de Cyperus iria L.; d) Efectos de cultivos sobre malezas: Ahn y Chung (2000), inhibición de la germinación y el crecimiento de plántulas de Echinochloa crusgalli por los extractos de cáscara de arroz; García, et al. (2001), acción supresora del millo, girasol y maíz contra $R$. cochinchinensis, E. indica, P. cleracea y $P$. hysterophorus, $S$. halepense y C. rotundus. Datos que pueden ser de gran valor al momento de decidir una posible secuencia de los cultivos a establecer en un terreno dado, en función de disminuir los efectos entre un cultivo y otro, buscando a la vez un control natural de las malezas.

Los efectos observados sobre la germinación y crecimiento de las plántulas de ajonjolí tienen explicación en la posible diversidad de la naturaleza química de los compuestos del corocillo presentes en los extractos, los cuales tuvieron un modo de acción directo dadas las condiciones controladas en las que se llevó a cabo el ensayo. Guedes et al. (2002) confirmaron la presencia en extractos de la parte aérea de Cyperus rotundus L. de: a) Fenoles: compuestos correlacionados con alteraciones en la actividad de las fitohormonas, división celular, síntesis 
orgánica, flujo de carbono, contenido de clorofila, absorción de agua y nutrimentos; b) Flavononas: interfieren en la síntesis de ATP mitocondrial, cadena de transporte de electrones y fotofosforilación; c) Saponinas: reducen la permeabilidad del tegumento de las semillas al oxígeno; d) Taninos condensados: inhiben la acción de las giberelinas, importantes para la germinación de las semillas; e) Terpenoides: sesquiterpenos específicos utilizados en las medicinas china y japonesa como analgésico y para el tratamiento de disturbios estomacales e intestinales; sin embargo, no se sabe si estas sustancias pueden interferir en la germinación de las semillas. De estos pareciera que las saponinas del corocillo tienen un mayor efecto detrimental sobre la germinación.

Komai et al. (1991) reportaron cuatro principales quimiotipos de corocillo ( $\mathrm{H}, \mathrm{M}, \mathrm{K}$ y O) basados en la composición de los aceites esenciales en tubérculos maduros. Estos autores reportaron que la actividad inhibitoria de estos aceites esenciales en contra el crecimiento de plántulas de lechuga y avena estuvo en el orden de $\mathrm{H}>\mathrm{M}>\mathrm{K}>\mathrm{O}$ y aislaron siete sesquiterpenos principales a partir de los aceites y determinaron sus actividades inhibitorias; sus resultados sugirieron que el corocillo de diferentes quimiotipos puede tener una actividad alelopática diferente en la interacción cultivo-maleza. MeroMacías (1996) indicó que las cualidades alelopáticas de corocillo ( $C$. rotundus) son: es común encontrar "monocultivos" en infestaciones de moderadas a altas aun cuando no se haya usado ninguna medida de control de malezas anuales; los exudados inhiben el crecimiento de cebada; la siembra en suelos previamente infestados reduce la germinación de cebada, algodón y mostaza; los suelos incubados con piezas de tubérculos y rizomas inhiben el crecimiento radical de los cultivos; el crecimiento de la cebada fue inhibido de 15 a $25 \%$ por los residuos (1-3 meses de descomposición) y la acumulación de biomasa de la soya y el sorgo se redujo con la presencia de los tubérculos o el follaje, mientras que para $C$. esculentus son: a) tejidos secos pueden inhibir el crecimiento y desarrollo de otras plantas; los residuos de los tubérculos causan una mayor inhibición del crecimiento y desarrollo del maíz y soya que los residuos del follaje; la soya es más susceptible a los residuos de $C$. esculentus que el maíz; los extractos acuosos causaron una inhibición de la germinación y el crecimiento de Amaranthus retroflexus, Echinochloa crusgalli y Chenopodium album y se cree que el efecto alelopático es causado por compuestos fenólicos.

Los resultados aquí presentados indican la susceptibilidad del cultivo de ajonjolí variedad Arapatol S-15, ante compuestos del corocillo, bajo las condiciones controladas del estudio, al ser inhibidores de la germinación de semillas y el crecimiento de plántulas del mismo. En este trabajo se restringe la discusión a hablar en términos de fitotoxicidad y en pocos casos de efectos fitoestimulatorios más que de alelopatía, tal cual como es señalado por Al Hamdi et al. (2001), quienes creen que los experimentos llevados a cabo bajo condiciones controladas no pueden nunca confirmar alelopatía operable en la naturaleza, y evitan el término alelopatía en la discusión y usan el término fitotoxicidad en su lugar, porque el término es a menudo mal empleado.

Es frecuente la preocupación acerca de la relevancia de los bioensayos de laboratorio para alelopatía (Connell, 1990; Inderjit y Olofsdotter, 1998; Inderjit y Dakshni, 1995, citados por Al Hamdi et al. 2001). El término alelopatía, según Al Hamdi et al., no debiera ser usado para designar la inhibición del crecimiento debido a sustancias químicas, hasta no disponer de datos sobre (i) la liberación natural de los compuestos desde la planta agresiva, (ii) la concentración y persistencia de estos compuestos en el ambiente, y (iii) el involucramiento directo de estos compuestos con la inhibición de la planta receptora, la cual puede ser demostrada por estudios de fijación; sin embargo, se puede usar el término fitotoxicidad. Willis, citado por dicho autor, presentó una lista de seis puntos como protocolo necesario para demostrar alelopatía en sistemas naturales: “(i) debe ser descrito un modelo de inhibición de una especie o planta por otra", (ii) la planta putativa agresiva debe producir una toxina, (iii) debe haber allí un modo de liberar la toxina desde la planta hacia el ambiente, (iv) debe ser la toxina transportada y/o acumulada en el ambiente, (v) la planta afligida debe tener algún medio de captación de la toxina, y (vi) el modelo de inhibición observado no puede explicarse únicamente por factores físicos u otros factores bióticos, especialmente por competencia y la lucha entre plantas. Blum et al., citado por $\mathrm{Al}$ Hamdi et al. (2001), recientemente concluyeron que ningún estudio alguna vez ha demostrado todos estos criterios. La naturaleza es en sí misma dinámica para ser únicamente explicada por un 
mecanismo de interferencia de plantas. El modelo de crecimiento observado es mejor explicado por una acción sinergística de varios mecanismos de interferencia (Indert y Del Moral, citados por Al Hamdi et al., 2001). Es casi imposible demostrar alelopatía siguiendo los seis criterios anteriores.

Debido a la existencia de un efecto generalmente negativo de los extractos acuosos foliares de corocillo sobre la germinación de semillas y el crecimiento de plántulas de ajonjolí variedad Arapatol S-15, es necesario considerar adicionalmente los efectos de competencia del corocillo por luz, agua y nutrimentos, los efectos detrimentales de la maleza per se en un programa de manejo integrado de malezas en ajonjolí en aquellos lugares donde predomine esta planta.

\section{LITERATURA CITADA}

AHN, J. K. and CHUNG I. M. 2000. Allelopathic potential of rice hulls on germination and seedling growth of barnyardgrass. Agronomy Journal, Vol. 92:1162-1167.

AL HAMDI, B.; OLOFSDOTTER, M. and STREIBIG, J.C. 2001. Laboratory Bioassay for phytotoxicity: An example from wheat straw. Agronomy Journal, Vol. 93:43-48.

ARNAUDE, O.; BRACHO, B. y PERAZA, S. 2001. Potencial alelopático de extractos acuosos y orgánicos de Pteridium aquilinum sobre semillas de Lactuca sativa. In XV Congreso de la Asociación Latinoamericana de Malezas. X Jornadas Venezolanas Científico-Técnicas en Biología y Combate de Malezas. Maracaibo. pp. 190.

ÁVILA, M. J. 1999. Cultivo del ajonjolí (Sesamum indicum L.). Maracay, Venezuela. Fondo Nacional de Investigaciones Agropecuarias. Centro de Investigaciones Agropecuarias del Estado Portuguesa. pp 66.

BORGHETTI, F.; DE CARVALHO R.; SILVA, L.; PINHEIRO, J. D.; VARELLA, B. B. and FERREIRA, A. G. 2005. Aqueous leaf extract properties of Cerrado species in Central Brazil. Proceedings of the 4th World Congress on Allelopathy, eds. J. D. I. Harper, M. An, H. Wu and J. H. Kent, Charles Sturt University, Wagga Wagga, NSW, Australia. August 2005. International Allelopathy Society. http://www. regional.org.au/au/allelopathy/2005/2/2/2443_borghettif. htm. Última visita 11 de marzo de 2006.

CÁRDENAS C., H. 1992. El corocillo (Cyperus rotundus L.): La maleza y su uso potencial. Imprenta universitaria de la Universidad Central de Venezuela. Colección Rectorado. Facultad de Agronomía, Instituto de Botánica. Maracay, Venezuela. $142 \mathrm{p}$.

CASTRO, P. R. C.; RODRÍGUEZ, J. D.; MORAES, M. A. e CARVALHO, V. L. M. 1983. Efeitos alelopãticos de alguns extratos vegetais na germinação do tamateiro (Lycopersicum esculentum Mill. Cv. Santa Cruz). Planta Daninha VI (2): 79-85.

GARCÍA, R.; PAREDES, E. y PÉREZ, E. 2001. Alelopatía de plantas cultivables como alternativa ambientalista para

\section{CONCLUSIONES}

1.- $\mathrm{El} \mathrm{pH}$ disminuyó y la CE se incrementó con los aumentos en la concentración de extractos foliares.

2.- La germinación fue inicialmente estimulada (concentraciones de 0,5 y $1,0 \%$ ), y posteriormente decreció (concentraciones de 1,5 y 2,0\%).

3.- El crecimiento presentó un estímulo inicial a nivel de la relación altura de la plántula/longitud de la radícula (concentraciones de 0,5 y $1,0 \%$ ) y luego disminuyó en las concentraciones mayores $(1,5$ y $2,0 \%)$. La altura de las plántulas, longitud de las radículas y los respectivos pesos secos de estos órganos disminuyeron con el incremento de la concentración del extracto.

el control de malezas. In XV Congreso de la Asociación Latinoamericana de Malezas. X Jornadas Venezolanas Científico-Técnicas en Biología y Combate de Malezas. Maracaibo. pp. 295.

GUEDES, C. M.; MELO DE SOUZA, C.; DE MORAIS, V.; ALVES DE CARVALHO, G. e DE PAIVA F., S. 2002. Efeitos de extratos aquosos de tiririca sobre a germinação de alface, pimentão e jiló e sobre a divisão celular na radícula de alface. Ceres. 49(281):1-11.

JERÔNIMO, C. A.; BORGHETTI, F. and MARTINS DE SÁ, C. 2005. Allelopathic effect of Solanum lycocarpum leaf extract on protein synthesis in sesame seedlings. Brazil. Proceedings of the 4th World Congress on Allelopathy, eds. J. D. I. Harper, M. An, H. Wu and J. H. Kent, Charles Sturt University, Wagga Wagga, NSW, Australia. August 2005. International Allelopathy Society. http://www.regional.org. au/au/allelopathy/2005/2/3/2440_borghettif.htm. Última visita 11 de marzo de 2006.

KOMAI, K.; TANG, C. S. and NISHIMOTO, R. K. 1991. Chemotypes of Cyperus rotundus in Pacific Rim and Basin: distribution and inhibitory activities of their essential oils. Journal of Chemical Ecology 17 (1): 1-8.

MEISSNER, R.; NEL, P. C. and SMITH, N. S. H. 1982. The residual effect of Cyperus rotundus on certain crop plants. Agroplantae, 14: 47-53.

MÉNDEZ N.; J. R.; IBARRA P.; F. T. y MERAZO P., J. F. 2002a. Germinación de semillas y desarrollo de plántulas de tres híbridos de maíz (Zea mays L.) bajo soluciones osmóticas I. Cloruro de sodio. VI Festival del Maíz. VI Jornada Científica Nacional del Maíz. Del 20 al 23 de noviembre del 2002. Maracay, Estado Aragua. On line: http://www.ceniap.gov.ve/vijornadasmaiz/trabajos/carteles/tecnosemilla/jmarquezsodio.htm. Última visita $28 \mathrm{de}$ junio de 2004.

MÉNDEZ N., J. R.; IBARRA P., F. T. y MERAZO P., J. F. 2002b. Germinación de semillas y desarrollo de plántulas de tres híbridos de maíz (Zea mays L.) bajo soluciones osmó- 
ticas II. Sulfato de sodio. VI Festival del maíz. VI Jornada Científica Nacional del Maíz. Del 20 al 23 de noviembre del 2002. Maracay, Estado Aragua. On line: http.//www.ceniap. gov.ve/vijornadasmaiz/trabajos/carteles/tecnosemilla/jmendezsulfato.htm. Última visita 28 de junio de 2004.

MERO-MACÍAS, H. 1996. The Weedy Nutsedges (Cyperus spp.) Outline. http://www.agron.iastate.edu/ weeds/weedbiollibrary/u4nutsg1.html. Última visita 04 de abril de 2006.

SAMPIETRO, D.A. 2002. Alelopatía: Concepto, características, metodología de estudio e importancia. Cátedra de Fitoquímica.
Instituto de Estudios Vegetales "Dr. Antonio R. Sampietro" Facultad de Bioquímica, Química y Farmacia. Universidad Nacional de Tucumán Ayacucho On line: http://fai.unne. edu.ar/biologia/plantas/alelopatia.htm. Última visita 12 de enero del 2006.

OLIVEIRA, S. C. C.; FERREIRA, A. G. and BORGHETTI, F. 2004. Allelopathic effect of Solanum lycocarpum St. Hil. leaves on the germination and growth of Sesamum indicum L. under different temperatures. Acta Botanica Brasilica 18(3): 401-406. 